\title{
Improvement of Shoulder Function after Teres Major Transfer and Subscapularis Sliding in Obstetric Brachial Plexus Palsy
}

\author{
MOHAMED A. AMIN, M.Sc.; HISHAM ABDEL GHANI, M.D.; MOSTAFA MAHMOUD, M.D. and \\ MOHAMED ABDEL WAHED KOTB, M.D.
}

The Department of Orthopedic Surgery, Faculty of Medicine, Cairo University

\begin{abstract}
Background: Obstetrical brachial plexus injury occurs as a result of forceful traction of the upper extremity for a long period of time during delivery and/or compression injury. Which result in internal rotation contracture of the shoulder and loss of external rotation. which may benefit from release of the contracture, tendon transfers.

Aim of Study: This study we do teres major transfer and subscapularis sliding and measure shoulder function improvement.

Patients and Methods: We conducted a randomized trail study over 20 patients with internal rotation contracture due to obstetric brachial plexus palsy. From 2015 to 2017 in Abo El Resh Hospital. We done subscapularis sliding combined with Teres major transfer for. The mean age at the time of operation was 2 years. We used modified gilbert score to asset shoulder function pre and postoperative.

Results: All patient after surgery show marked improvement of shoulder abduction and external rotation. Severe external rotation contracture occurred in 3 patients.

Conclusion: After subscapularis sliding with teres major transfer have perfect result in improving of shoulder function with increase the risk of external rotation contracture after transfer.
\end{abstract}

Key Words: Obstetric brachial plexus palsy - Internal rotation contracture - Teres major - External contracture.

\section{Introduction}

THE most common type in pediatric injury of the upper limb is upper brachial plexus injury [1]

Obstetrical brachial plexus injury occurs as a result of forceful traction of the upper extremity for a long period of time during delivery and/or compression injury [2].

Spontaneous recovery is seen in $80 \%$ to $90 \%$ of the cases with obstetrical brachial plexus injury.

Correspondence to: Dr. Mohamed A. Amin, E-Mail: mohhemila@gmail.com
The clinical presentation of the patient may vary based on the extent of injury to the brachial plexus, number of injured nerves, and the degree of injury. The most frequent involvement occurs in the upper plexus (C5-6) [3]

In cases of upper plexus injuries without full recovery, the most common problems include decreased external rotation and abduction and deformity of the glenohumeral joint secondary to internal rotation contracture of the shoulder [4].

Patients with internal rotation contracture of the shoulder and loss of external rotation may benefit from reconstructive surgical procedures including arthroscopic or open release of the contracture, tendon transfers, and rotational osteotomy [5].

In this randomized trail we study the result of teres major transfer and subscapularis sliding. And assess the shoulder function by modified gilbert score.

\section{Patients and Methods}

We treated 20 patients age between 1.5 year to 10 years with unilateral incomplete brachial plexus injury. From 2015 to 2017 in Abo El Resh Hospital. All patient had the following inclusion criteria which is $1.5-10$ years of age with internal rotation contracture (less than $20^{\circ}$ passive external rotation of the shoulder in adducted position) with minimum active abduction of $30^{\circ}$.

Active triceps grade 3 according to MRC motor power scale.

In infants less than 2 years should have impending or true dislocation of gleno-humeral joint diagnosed by clinical examination in the form of severe internal rotation contracture and the presence of anterior skin crease to be candidate for transfer. 
We treated these patients by subscapularis sliding and teres major transfer.

\section{We evaluated the patient in the following manner:}

All patients were examined upon the entry to the hospital, before and after surgery, at 2, 3,4,5,6 months after surgery.

Patients were assessed as follow:

- Assess the passive external rotation in abduction and adduction.

- Presence of abduction contracture, external rotation contracture.

- Active global abduction.

- Active external rotation.

Classification was done by Ghani modification of gilbert score for infant younger than 6 years and modified mallet score for 6 years and older children.

And the average postoperative follow-up is 20 months. The data collected included age, sex, type of lesions, pre- and post- operative recording of active and passive shoulder abduction and external rotation and the external rotation contracture by modified mallet score.

\section{Surgical technique:}

Patient after being anaesthetized, was lied in lateral decubitus while the affected side being up. At the start of this surgery, assessment of the passive range of movement (PROM) around the shoulder joint is so essential. Any internal rotators contracture is to be considered. A curvilinear incision from the inferior angle of scapula the posterior of lateral border of acromion was done. Subcutaneous dissection was done by diathermy, identification of the fascia of latissimus dorsi was done by dissecting scissor dissection was continued anterior to the lateral border of latissimus dorsi muscle and neurovascular bundle of the latissimus dorsi was identified and protected. The anterior border of the latissimus was retracted posteriorly and deeper dissection was carried out to expose the anterior surface of the scapula and subscapularis muscle. With a towel clip the inferior angle of the scapula was held. The subscapularis muscle was incised from its origin by diathermy along the medial border of scapula and sliding was done by periosteal elevator and passive external rotation was assessed after sliding.
Conjoint tendon was identified release of Teres major part from latissimus dorsi was done by blunt dissection. Axillary connection was identified and excised. Shoulder was brought in abduction and internal rotation to approximate the insertion of both tendons in the bicipital groove (teres major in the medial border) and graft of teres major tendon was harvested. After that, the arm adjusted in $90^{\circ}$ abduction, $90^{\circ}$ external rotation, then the posterior fibers of the deltoid was elevated. The supra and infra spinatous tendon was identified and with right angle a tunnel was created below them the harvested latissimus or teres major tendon was delivered to create loop around supra and infra spinatous tendon fixation of graft was done by non-absorbable suture. Subcutaneous and skin closure was done. Shoulder Spica was done in $90^{\circ}$ external rotation $60^{\circ}$ abduction.

Patient was dismissed from the hospital 2 days after the surgery. 1 follow-up was after 2 weeks to check the cast wound and take the measurement of abduction brace.

2 nd follow-up was at 1.5 -month post-operative for cast removal and the patient was instructed to do physiotherapy and to wear the abduction brace at bed time. Then Follow-up was done every month for 2 years (Figs. 1-5).

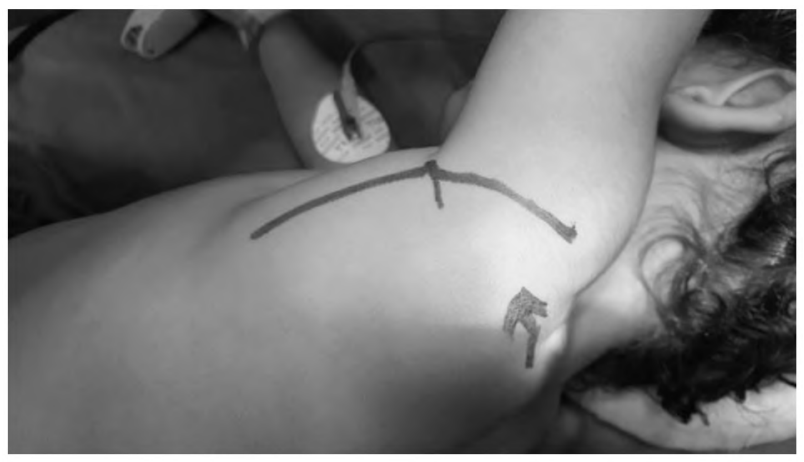

Fig. (1): Skin incision.

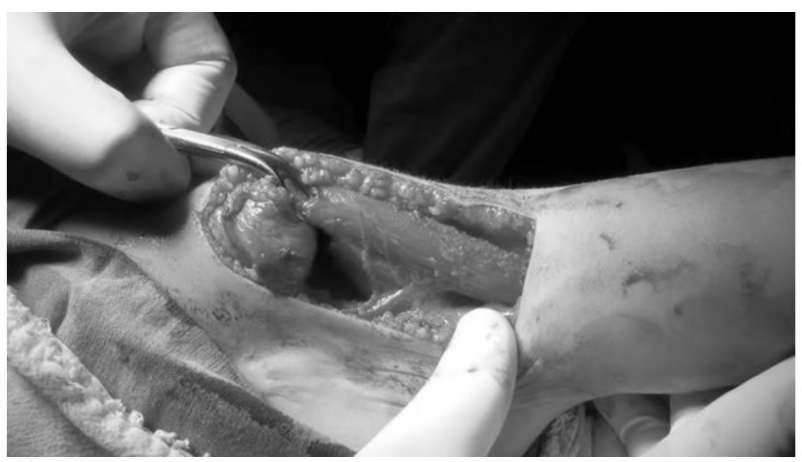

Fig. (2): Subscapularis sliding. 


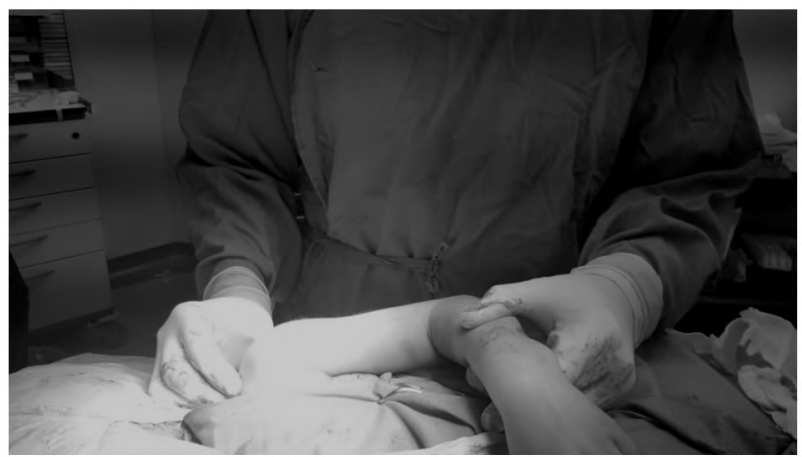

Fig. (3): Intra operative passive external rotation before subscapularis sliding.

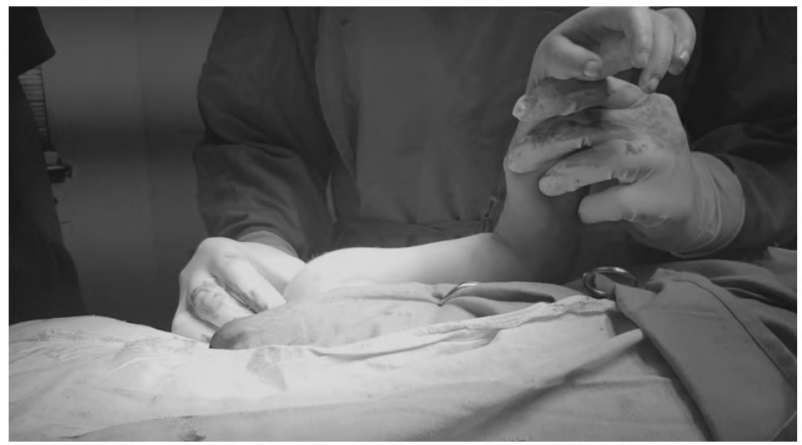

Fig. (4): Intraoperative passive external rotation post subscapularis sliding.

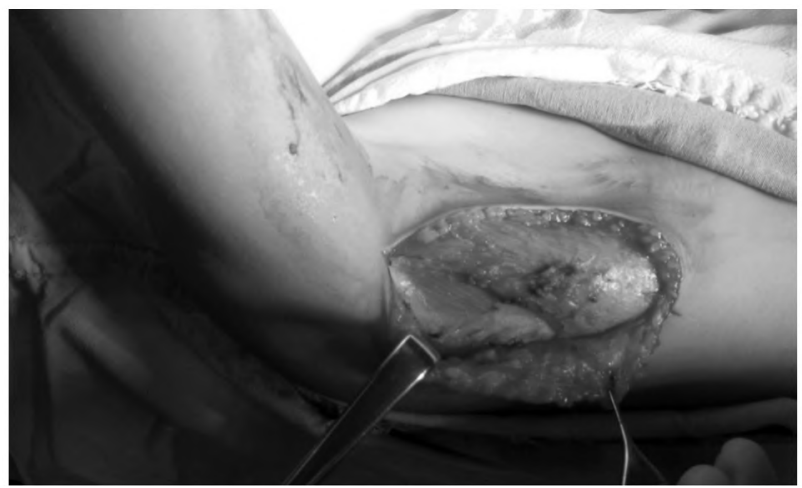

Fig. (5): Interval between latissimus dorsi and Teres major muscle.

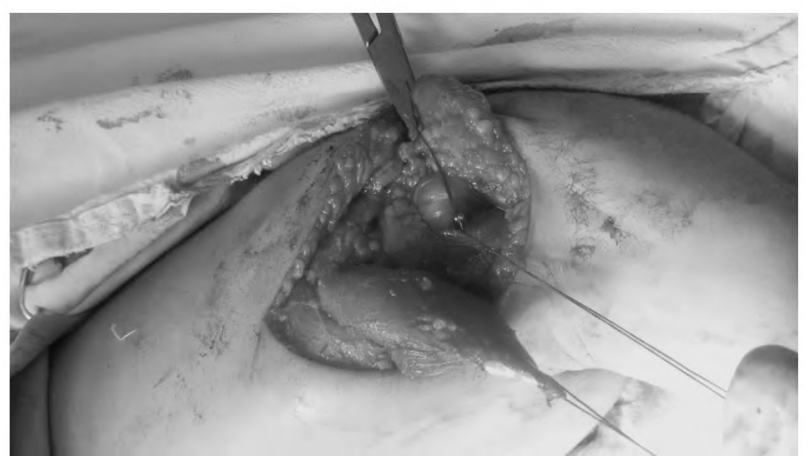

Fig. (6): Teres major tendon harvesting.

\section{Results}

We operated on 20 patients From 2015 to 2017 in Abo El Resh Hospital. A prospective randomized study was performed to treat the OBBP internal rotation contraction with limited shoulder abduction.

Patients undergoing subscapularis sliding and teres major.

All patients' parents were satisfied with the final outcome and felt there had been improvement of function and appearance of their children. There was significant improvement of shoulder abduction in all patients from mean 74 degree preoperatively to mean 125 degree post operatively with the difference between preoperative and postoperative shoulder abduction is statistically significant.

\section{Change in range of motion:}

There was marked improvement of shoulder abduction from 70 degree preoperative to 140 degree postoperative with the difference between preoperative and postoperative shoulder abduction is statistically significant.

There was marked improvement of active external rotation from 15 degree preoperative to 90 degree postoperative, and marked improvement of the preoperative passive external rotation from 4 degree to 90 degree postoperative with the difference between pre and postoperative external rotation is statistically significant (Table 1).

Preoperative active shoulder abduction was 70 degree and postoperative was 140 degree. The preoperative passive external rotation in adduction was -4 degree and the postoperative external rotation in adduction was 90 degree.

There was marked improvement of mean postoperative shoulder abduction, active and passive external rotation which was significantly different between the preoperative and postoperative measures in both groups but there was no significant difference in the improvement degrees between both groups (Table 2).

There was significant improvement of modified gilbert score from grade IIa preoperatively to grade $\mathrm{Va}$ and $\mathrm{Vb}$ post operatively in both group with no significant difference between the 2 groups. Severe (grade 1) external rotation contracture occurred in 3 patients. 
Table (1): Shoulder motion measures.

\begin{tabular}{|c|c|c|c|c|c|}
\hline & \multirow{2}{*}{$\begin{array}{l}\text { Shoulder } \\
\text { abduction }\end{array}$} & \multirow{2}{*}{$\begin{array}{l}\text { Passive } \\
\text { external } \\
\text { rotation }\end{array}$} & \multirow{2}{*}{$\begin{array}{l}\text { Active } \\
\text { external } \\
\text { rotation }\end{array}$} & & Grades \\
\hline & & & & Mean preoperative passive external rotation in & -4.00 \\
\hline Mean preoperative & 70 & -4 & 15 & $\begin{array}{l}\text { Mean preoperative active external rotation } \\
\text { Mean preoperative external rotation in abduction }\end{array}$ & $\begin{array}{l}15 \\
86.25\end{array}$ \\
\hline Mean postoperative & 1140 & 90 & 90 & $\begin{array}{l}\text { Mean preoperative shoulder abduction } \\
\text { Mean postoperative shoulder abduction }\end{array}$ & $\begin{array}{l}70.00 \\
140.00\end{array}$ \\
\hline$p$-value & 0.001 & 0.001 & 0.005 & $\begin{array}{l}\text { Mean postoperative passive external rotation } \\
\text { Mean postoperative active external rotation }\end{array}$ & $\begin{array}{l}90.00 \\
90.00\end{array}$ \\
\hline
\end{tabular}

Table (3): Master sheet.

\begin{tabular}{|c|c|c|c|c|c|c|c|c|c|c|}
\hline \multirow[b]{2}{*}{ Age } & \multirow[b]{2}{*}{$\begin{array}{c}\text { Limb } \\
\text { involved }\end{array}$} & \multirow[b]{2}{*}{$\begin{array}{c}\text { Tendon } \\
\text { transfered }\end{array}$} & \multicolumn{4}{|c|}{ Pre-operative } & \multicolumn{4}{|c|}{ Post-operative } \\
\hline & & & $\begin{array}{c}\text { Passive } \\
\text { ext.rotation } \\
\text { in adduction }\end{array}$ & $\begin{array}{c}\text { Passive } \\
\text { ext.rotation } \\
\text { in abduction }\end{array}$ & $\begin{array}{l}\text { Active } \\
\text { external } \\
\text { rotation }\end{array}$ & $\begin{array}{l}\text { Active } \\
\text { abduction }\end{array}$ & $\begin{array}{c}\text { Passive } \\
\text { ext.rotation } \\
\text { in adduction }\end{array}$ & $\begin{array}{l}\text { Active } \\
\text { external } \\
\text { rotation }\end{array}$ & $\begin{array}{c}\text { Active } \\
\text { abduction }\end{array}$ & $\begin{array}{l}\text { External } \\
\text { rotation } \\
\text { contracture }\end{array}$ \\
\hline 3 & Left & Teres major & 0 & 90 & $(<0-0)$ & 60 & 90 & 90 & 120 & Grade 1 \\
\hline 2.5 & Left & Teres major & 0 & 90 & $\left(>0-30^{\circ}\right)$ & 70 & 90 & 90 & 150 & Grade 2 \\
\hline 2 & Right & Teres major & 0 & 90 & $\left(>0-30^{\circ}\right)$ & 45 & 90 & 90 & 160 & Grade2 \\
\hline 2 & Right & Teres major & -30 & 45 & $(<0-0)$ & 80 & 90 & 90 & 150 & Grade 2 \\
\hline 5 & Right & Teres major & 0 & 90 & $\left(>0-30^{\circ}\right)$ & 70 & 90 & 90 & 120 & Grade 1 \\
\hline 2.5 & Right & Teres major & 0 & 90 & $\left(>0-30^{\circ}\right)$ & 70 & 90 & 90 & 160 & Grade 3 \\
\hline 2 & Left & Teres major & 0 & 90 & $\left(>0-30^{\circ}\right)$ & 60 & 90 & 90 & 150 & Grade 2 \\
\hline 3 & Right & Teres major & 0 & 90 & $\left(>0-30^{\circ}\right)$ & 70 & 90 & 90 & 150 & Grade 3 \\
\hline 2 & Left & Teres major & 0 & 90 & $(<0-0)$ & 70 & 90 & 90 & 90 & Grade 2 \\
\hline 2 & Right & Teres major & 0 & 90 & $\left(>0-30^{\circ}\right)$ & 70 & 90 & 90 & 160 & Grade 3 \\
\hline 2 & Left & Teres major & 0 & 90 & $\left(>0-30^{\circ}\right)$ & 80 & 90 & 90 & 100 & Grade 3 \\
\hline 2 & Left & Teres major & -10 & 90 & $\left(>0-30^{\circ}\right)$ & 80 & 90 & 90 & 100 & Grade 3 \\
\hline 3 & Right & Teres major & -10 & 60 & $\left(>0-30^{\circ}\right)$ & 80 & 90 & 90 & 150 & Grade 3 \\
\hline 1.3 & Right & Teres major & 0 & 90 & $(<0-0)$ & 45 & 90 & 90 & 150 & Grade 2 \\
\hline 3 & Right & Teres major & 0 & 90 & $\left(>0-30^{\circ}\right)$ & 80 & 90 & 90 & 100 & Grade 1 \\
\hline 1.8 & Right & Teres major & -30 & 90 & $(<0-0)$ & 70 & 90 & 90 & 150 & Grade 3 \\
\hline 4 & Left & Teres major & 0 & 90 & $\left(>0-30^{\circ}\right)$ & 80 & 90 & 90 & 100 & Grade 2 \\
\hline 1.2 & Right & Teres major & 0 & 90 & $\left(>0-30^{\circ}\right)$ & 80 & 90 & 90 & 130 & Grade 2 \\
\hline 5 & Right & Teres major & 0 & 90 & $\left(>0-30^{\circ}\right)$ & 80 & 90 & 90 & 100 & Grade 2 \\
\hline 5 & Right & Teres major & 0 & 90 & $(<0-0)$ & 60 & 90 & 90 & 140 & Grade 3 \\
\hline
\end{tabular}

\section{Discussion}

In our study, we discuss the benefit of single tendon transfer with subscapularis sliding and the function improvement and the incidence of complication.

We operated on 20 patients. All patients underwent subscapularis sliding and Teres major transfer. The patients were followed-up for 2 years post operatively. This is considered moderate size sample but with short follow-up period compared to other studies. In Gilbert series, he operated on 1486 patients and the follow-up for 10 years [3] Al-Qattan operated on 12 patients and the follow up was for 4 years. Abdel Ghani, operated on 63 patients and the follow-up was for 19 months [7] Amador operated on 24 patients and the followup was 2 years [8]. Al-Anani, operated on 50 patients and the follow-up was 4 years [9]. Kirkos, operated on 10 patients and follow-up was 30 years. Terzis, operated on 197 patients and the follow-up was 7.5 years [10].

We used Ghani modification of Gilbert score for patients younger than 6 years and modified mallet score for patients older than 6 years. Abdel Ghani, used modified gilbert score in his study [8] Al-Qattan, Al-Anani, Kirkos and Terzis used modified mallet score [7,10]. Amador, used gilbert score to assess shoulder function [9]. The main defect in modified Gilbert score is that it does not assess external rotation contracture. But in our study, we assessed external rotation contracture in every patient regardless of the scoring method.

We found that there was no relation between the age of the patient and the improvement of the shoulder range of motion after tendon transfer, this may be because most of our patients were younger than 5 years. Pearl noticed that a remodeling of the glenohumeral joint does occur at all ages, but 
the most impressive remodeling of the glenohumeral anatomy has been reported to occur in younger children [11]. Al-Qattan reported that best result for muscle transfer occurred in young patients with no secondary deformity [12]. Al-Anani, reported that tendon transfer has best result under the age of 5 years [7]

In our study, we notice significant improvement in shoulder abduction and external rotation. Abdel Ghani, [13] noticed that significant improvement of shoulder abduction and external rotation after Teres major muscle and Latissimus transfer with subscapularis sliding. Reda et al., [14] noticed marked improvement of shoulder abduction external rotation with transfer of latissimus to greater tuberosity and Teres to lesser. Anani [10], noticed that significant improvement of shoulder abduction by 40 degree and external rotation by 35 degree, after Teres and latissimus transfer to rotator cuff. Al-Qattan [13] found that improvement of external rotation from 0 to 30 degree with more improvement of shoulder abduction occurred after Latissimus dorsi tendon transfer to rotator cuff, and he referred that improvement of shoulder abduction to increase of shoulder stability after tendon transfer.

We observed that patients with passive external rotation in adduction less than 0 degree preoperatively is accompanied with posterior shoulder subluxation that was found in 3 patients.

In our study after subscapulairs sliding and tendon transfer there was loss of some internal rotation degrees but not to disabling limit. This incidence is higher in patients with extended brachial plexus palsy, this may be due to that Teres major is stronger internal rotator than latissimus and with subscapularis release and Teres major transfer we lose more internal rotation power and add strong external rotator. Another theory is that in extended brachial plexus palsy internal rotation motion is mainly from the glenohumeral joint motion not like upper brachial plexus which is mainly from scapulothoracic joint.

Peter Waters noticed that in appropriately selected patients, latissimus dorsi and Teres major tendon transfers to the rotator cuff combined with musculotendinous lengthening and open glenohumeral joint reduction not only improve upper extremity function but also remodel the glenohumeral dysplasia present in the majority of patients and the improvement in external rotation was not on the expense of internal rotation [15] . AbdelGhani, noticed that complete release of internal rotation contracture after subscapularis release, lead to loss of some degree of internal rotation and the loss of internal rotation was less in single latissimus dorsi tendon transfer than combined Teres major and latissimus dorsi transfer [8]. Kambhampati (2006) observed that 10-degree loss in internal rotation after subscapularis sliding, but more loss of internal rotation up to 42 degree after arthroscopic tenotomy of the subscapularis tendon [16] . Bertelli, reported about 20-degree loss of internal rotation. We thought that this difference in the result might be due to the greater preoperative internal rotation contracture degrees in comparison with those in the series of Kambhampati [17]. Van der Sluijs. Reported that the incidence of severe external contracture occurred in $42 \%$ after subscapularis tendon lengthening and open reduction of the shoulder and that was necessitating to do derotation humeral osteotomy to treat the severe external rotation contracture [18]

Pearl (2006) assumed that arthroscopic release of the capsule as a part of the subscapularis sliding and latissimus dorsi transfer is efficient to treat internal rotation contracture. However, he reported a $100 \%$ incidence of external rotation contracture. He mentioned that after release was done, some degree external rotation contracture is inevitable [19]. Terzis and Kokkalis, reported that after release and latissimus dorsi and Teres major transfer there was difficulty in bringing the hand to the body for midline dressing tasks and that occurred in $28 \%$ of patients [20].

\section{Conclusion:}

Subscapularis sliding and Teres major transfer give significant improvement of the shoulder function in patients with internal rotation contracture. Our result show marked improvement of the shoulder abduction and external rotation, although there is higher incidence of development of external rotation contracture after Teres major transfer.

\section{References}

1- POLLACK R.N., BUCHMAN A.S., YAFFE H. and DIVON M.Y.: Obstetrical brachial palsy: Pathogenesis, risk factors, and prevention. Clin. Obstet. Gynecol., 43: 236-46, 2000

2- PEARL M.L.: Shoulder problems in children with brachial plexus birth palsy: Evaluation and management. J. Am. Acad. Orthop. Surg., 17: 242-54, 2009.

3- GILBERT A.: Long-term evaluation of brachial plexus surgery in obstetrical palsy. Hand Clin., 11: 583-94, 1995.

4- BENNETT J.B. and ALLAN C.H.: Tendon transfers about the shoulder and elbow in obstetrical brachial plexus palsy. Instr. Course Lect, 49: 319-32, 2000. 
5- WATERS P.M. and BAE D.S.: Effect of tendon transfers and extraarticular soft-tissue balancing on glenohumeral development in brachial plexus birth palsy. J. Bone Joint Surg. [Am.], 87: 320-5, 2005.

6- AL-QATTAN M.M.: Latissimus dorsi transfer for external rotation weakness of the shoulder in obstetric brachial plexus palsy. Journal of Hand Surgery, 28 B (5): $487-$ 490, 2003.

7- ABDEL-GHANI H., HAMDY K. A., BASHA N. and TARRAF Y.N.: Tendon transfer for treatment of internal rotation contracture of the shoulder in brachial plexus birth palsy. Journal of Hand Surgery (European Volume), 37 (8): 781-786, 2012.

8- VERGARA-AMADOR E.: Latissimus dorsi transposition for sequelae of obstetric palsy. Colombia Medica, 41 (3): 248-255, 2010.

9- MOHAMED AL ANANI: Shoulder Functional outcome after Latissimus Dorsi Muscle Transfer and Subscapularis Muscle Release in Children with Obstetrical Brachial Plexus Palsy. Journal of The Royal Medical Services, 22 (2): 45-50, 2015.

10- TERZIS J.K., VEKRIS M.D., OKAJIMA S. and SOUCACOS P.N.: Shoulder deformities in obstetric brachial plexus paralysis: A computed tomography study. J. Pediatr. Orthop, 23 (2): 254-260, 2003.

11- PEARL M.L. and EDGERTON B.W.: Glenoid deformity secondary to brachial plexus birth palsy. J. Bone Joint Surg. Am., 80: 659-667, 1998.

12-AL-QATTAN M.M.: Latissimus dorsi transfer for external rotation weakness of the shoulder in obstetric brachial plexus palsy. Journal of Hand Surgery, 28 B (5), 487-490, 2003.
13-REDA AHMAD M.: Bidirectional Double Muscle Transfer to Restore Shoulder Abduction and External Rotation in Late Obstetric Brachial Plexus Injuries. Surgery: Current Research, 05 (01): 1-5, 2014.

14- PETER M. WATERS and DONALD S. BAE: The Early Effects of Tendon Transfers and Open Capsulorrhaphy on Glenohumeral Deformity in Brachial Plexus Birth Palsy, J. Bone Joint Surg. Am., 90: 2171-2179, 2008.

15- KAMBHAMPATI S.B., BIRCH R., COBIELLA C. and CHEN L.: Posterior subluxation and dislocation of the shoulder in obstetric brachial plexus palsy. J. Bone Joint Surg. Br., 88: 213-219, 2006.

16-BERTELLI J.A.: Lengthening of subscapularis and transfer of the lower trapezius in the correction of recurrent internal rotation contracture following obstetric brachial plexus palsy. J. Bone Joint Surg Br., 91: 943-8, 2009.

17- VAN DER SLUIJS J.A., VAN OUWERKERK W.J., de GAST A., et al.: Treatment of internal rotation contracture of the shoulder in obstetric brachial plexus lesions by subscapular tendon lengthening and open reduction: Early results and complications. J. Pediatr. Orthop. B., 13: 21824, 2004.

18- PEARL M.L., EDGERTON B.W., KAZIMIROFF P.A., et al.: Arthroscopic release and latissimus dorsi transfer for shoulder internal rotation contractures and glenohumeral deformity secondary to brachial plexus birth palsy, J. Bone Joint Surg., 88A: 564, 2006.

19- TERZIS J.K. and KOKKALIS Z.T.: Outcomes of secondary shoulder reconstruction in obstetrical brachial plexus palsy. Plastic and Reconstructive Surgery, 122 (6): 181222, 2008.

\section{تحسن وظيفة الكتف بعل نقل العضلة الكبيرة المدورة

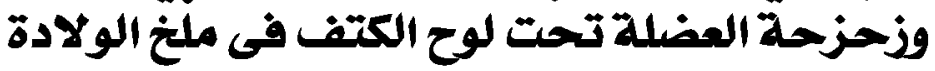

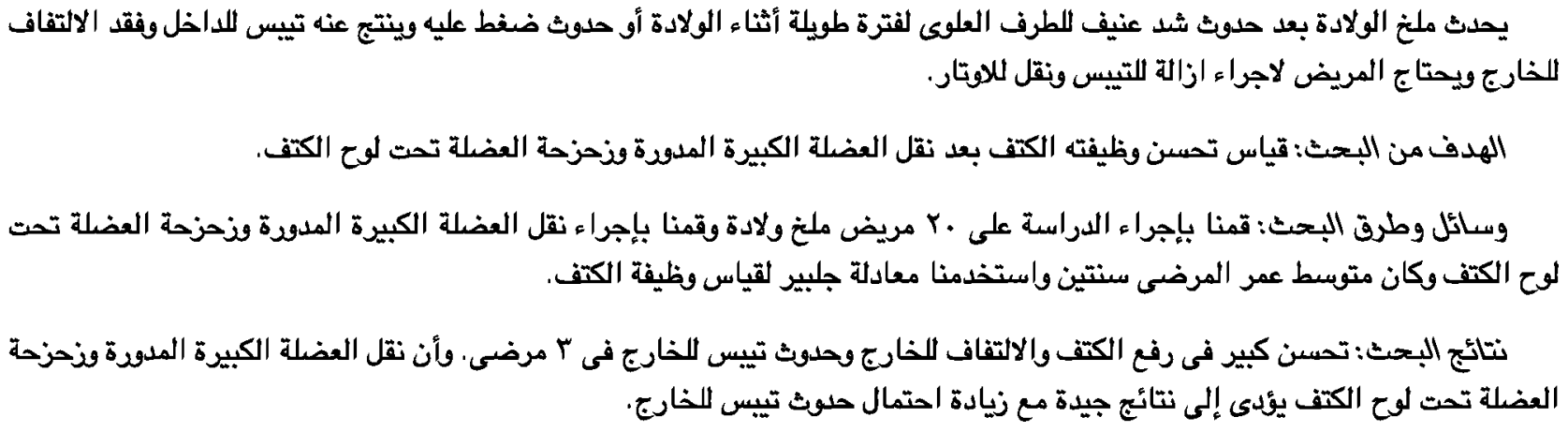

